\title{
PSYCHOLOGICAL STRESS AND ATOPIC DERMATITIS SEVERITY FOLLOWING THE COVID-19 PANDEMIC AND AN EARTHQUAKE
}

\author{
Liborija Lugović-Mihić $^{1,2}$, Jelena Meštrović-Štefekov ${ }^{1}$, Nives Pondeljak ${ }^{1}$, Marina Dasovićc ${ }^{1}$ \\ Mirna Tomljenović-Veselski ${ }^{3} \&$ Hrvoje Cvitanović $^{4}$ \\ ${ }^{I}$ Department of Dermatovenereology, University Hospital Center Sestre Milosrdnice, Zagreb, Croatia \\ ${ }^{2}$ School of Dental Medicine, University of Zagreb, Zagreb, Croatia \\ ${ }^{3}$ Department of Dermatology and Venerology, Dr. Josip Bencević General Hospital, Slavonski Brod, Croatia \\ ${ }^{4}$ Department of Dermatovenerology, Karlovac General Hospital, Karlovac, Croatia
}

received: 22.2.2021;

revised: 7.10.2021;

accepted: 12.10 .2021

\section{SUMMARY}

Background: The course of chronic diseases can be influenced by psychological stress, suggesting a potential influence of current/recent disasters on atopic dermatitis (AD) patients. The aim of the study was to examine effects of the COVID-19 pandemic and Zagreb earthquake on the psychological stress level and disease condition of AD patients.

Subjects and methods: This cross-sectional study included 150 AD patients (three groups with 50 patients): 1) those not exposed to either the COVID-19 pandemic or the earthquake; 2) those who only experienced the COVID-19 pandemic; and 3) those who experienced both the pandemic and the earthquake. Patients' data from the Perceived Stress Scale (PSS), on AD severity (SCORAD), and their answers from our newly designed questionnaire on disease-related behaviors and AD condition during the pandemic and quarantine were examined and statistically analyzed.

Results: The subjects who experienced both disasters had a greater PSS than those experiencing only the COVID-19 pandemic, especially women, and they also had higher disease severity (SCORAD) than those in the other two groups. Also, 59\% of patients reported psychological stress during the pandemic, mostly caused by: the possibility of infection (31\%), a changed work life and possible loss of income (23\%), general pandemic-related conditions (17\%), worry about physical survival (11\%) and other (6\%). Concerning the earthquake, the PSS significantly positively correlated with the psychological experience of the earthquake and with the intensity of sleep disturbances.

Conclusion: To the best of our knowledge, this is the first study to specifically confirm-that the COVID-19 pandemic influenced AD patients' stress levels and that stress from two disasters affected skin disease. Further research and therapeutic measures are needed.

Key words: atopic dermatitis - psychologic stress - COVID-19 pandemic - earthquake - quarantine

$* * * * *$

\section{INTRODUCTION}

Atopic dermatitis (AD) is a common, chronic allergic skin disease with a complex multifactorial etiopathogenesis influenced by a number of hereditary and environmental factors, primarily psychological stress (Oh et al. 2010, Suárez et al. 2012, Senra \& Wollenberg 2014, Meštrović-Štefekov et al. 2018, Rønnstadet al. 2018, Silverberg et al. 2019). It has been established that psychological stress affects the function of a person's neuroendocrine and immune systems, resulting in changes to the skin's epidermal barrier function, consequently affecting disease condition (Lugović-Mihić et al. 2013, Honeyman 2016, Lin et al. 2017, Choe et al 2018, Meštrović-Štefekov et al. 2018, Pondeljak \& Lugović-Mihić 2020). In addition to the influence of everyday psychological stress, extraordinary and unexpected negative stress, such as a catastrophe or human disaster, can also influence and further aggravate skin lesions. After the dramatic reports from China and Italy on COVID-19, Croatia identified its first patients with COVID-19 infection by the end of February 2020. Following a slow increase in cases, a lockdown was instituted with mandatory social isolation in quarantine, which lasted from 22 March to 5 May 2020. Then, on 22 March 2020 at 6:24 A.M., Zagreb, the capital of Croatia, experienced a 5.3 magnitude earthquake and 57 aftershocks in the 24 hours following (Čivljak et al 2020, Trkulja \& Hrabač 2020). A large number of buildings and houses were significantly damaged, especially those in the city center, and several hospitals and their patients had to be evacuated. In all, there were 27 reported injuries, including the unfortunate death of a 15-year-old girl.

Many studies have indicated that stressful events influence patients with chronic diseases; thus, we wanted to examine the impact of this extraordinary simultaneous set of events in Zagreb on the mental health of AD patients, specifically, any possible correlation between psychological stress levels and AD severity/ condition.

\section{SUBJECTS AND METHODS}

We performed this observational cross-sectional study to examine the impact of the COVID-19 pandemic and the earthquake in Zagreb (22 March 2020) on AD patients, ie. associated psychological stress and its 
influence on $\mathrm{AD}$ and the correlation between psychological stress level and disease condition (severity). The lockdown with quarantine in Croatia lasted from 22 March - 3 May, and groups 2 and 3 were enrolled immediately after its termination (4 May - 30 June 2020). Patient data were compared with the control group (Group 1), which had been examined previously (2018 and 2019).

\section{Subjects}

Samples were stratified by exposure using convenience quota sampling. Three groups of patients (150 patients total) were included. Each patient was diagnosed with $\mathrm{AD}$ and came to our clinic/office for a dermatologist visit in the period between 2018 and 2020 (when taking into account all sample of the three groups) were included. Group 1 included those not exposed to either the COVID-19 pandemic or the earthquake, meaning these patients were treated by a dermatologist in 2018 and/or 2019. The patients in the second and third groups (Group 2 and Group 3) were AD patients examined by dermatologists immediately after the end of the lockdown/quarantine (between 3 May and 30 June 2020). Therefore, patients in Group 2 experienced only the COVID-19 pandemic but not the earthquake (patients who did not live/were not present in Zagreb during the earthquake), while Group 3 experienced both the pandemic and the earthquake (patients who lived in Zagreb and closely surrounding areas), regardless of the strength of the earthquake in each patient's part of town. Thus, data/ results from groups 2 and 3 were compared with that of Group 1.

We recruited study participants from our pool of patients at the dermatology clinic (both first time and regular patients). For each of the three study groups, the first 50 patients who met the inclusion criteria were invited to participate. The inclusion criteria for all subjects were: legal adult age $(>18)$ and a diagnosis of AD according to the Hanifin and Rajka criteria, diagnosed/ treated by a dermatologist with valid medical documentation (Hanifin \& Rajka 1980). Inclusion criteria by study group were based on patients' exam/treatment dates, e.g. participants in Group 1 were seen only in 2018/2019 before the pandemic. Exclusion criteria were patients younger than 18 , insufficient medical data and those who changed their residence during the aforementioned time. A total of 150 patients, who signed a written informed consent, were enrolled in the study.

For each AD patient, disease severity was determined with the SCORAD index (Hanifin \& Rajka 1980, Kunz et al. 1997). All subjects completed a Perceived Stress Scale (PSS) (Cohen et al. 1983, Fazlić et al. 2012), while patients exposed to the COVID-19 pandemic additionally completed a selfadministrated questionnaire addressing disease-related behaviors and $\mathrm{AD}$ condition during the pandemic and quarantine isolation (Figure 1).

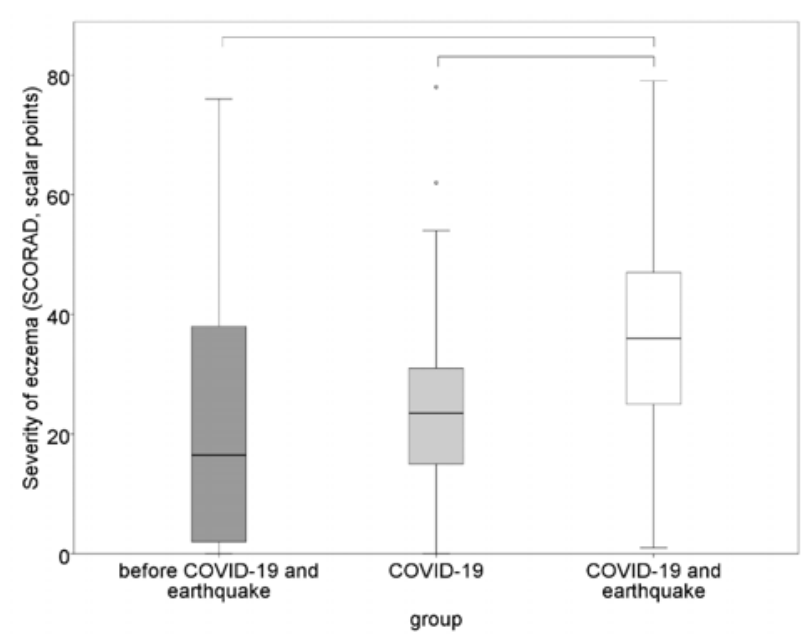

Figure 1. Comparison of eczema/disease severity between the three subject groups $(\mathrm{N}=150)$. Boxes represent interquartile ranges, lines within the boxes are medians, whiskers show maximal and minimal values, and dots show outlier values.

The study was performed with the approval of the Ethics Committee of the University Hospital Center Sestre milosrdnice (EP-20098/16-4, Class: 003-06/2003/009, Number: 251-29-11-20-01-1). The research was conducted in accordance with the guidelines of the Helsinki Declaration.

\section{Assesment of AD severity by the SCORAD index}

The SCORAD index of AD severity assessment takes into account both objective and subjective AD indicators (Kunz et al. 1997). SCORAD index assesses percentage of skin involved with each clinical characteristic, along with subjective symptoms of itch and sleeplessness (experienced in the three days prior to taking the questionnaire). The maximum SCORAD score is 103 - a score less than 25 is marked as mild, 25 to 50 is moderate, and a score greater than 50 indicates severe AD.

\section{Filling out the questionnaires}

Participants were asked to fill out two questionnaires: one on their stress levels (PSS) and one addressing their disease-related behaviors and $\mathrm{AD}$ condition during the pandemic and quarantine isolation.

\section{Perceived Stress Scale (PSS)}

All AD patients/subjects completed the PSS questionnaire, which is a validated instrument for psychological stress intensity measurement which asks respondents to look back over the last month (Cohen et al. 1983, Fazlić et al. 2012). The result of the questionnaire is expressed by the sum of the numerical values assigned to the answers as marked by the respondents. A sum result from 0-13 points is considered a low level of psychological stress, $14-26$ is moderate, and $27-40$ is a high level of psychological stress. 
Table 1. Questions used in study

\begin{tabular}{|c|c|c|c|c|c|c|}
\hline Question & Answer: 0 & Answer: 1 & Answer: 2 & Answer: 3 & Answer: 4 & Answer: 5 \\
\hline $\begin{array}{l}\text { 1. With regard to my atopic } \\
\text { dermatitis the last two months, } \\
\text { the severity of my disease } \\
\text { (deterioration) }\end{array}$ & did not change & small changes & $\begin{array}{l}\text { moderate } \\
\text { changes }\end{array}$ & major changes & & \\
\hline $\begin{array}{l}\text { 2. During the COVID- } 19 \text { pandemic, } \\
\text { concerning use of therapy for AD... }\end{array}$ & $\begin{array}{l}\text { I didn't use it } \\
\text { at all }\end{array}$ & rarely & $\begin{array}{l}\text { average/mediu } \\
\mathrm{m} \text { use }\end{array}$ & frequent use & & \\
\hline $\begin{array}{l}\text { 3. Psychological stress during the } \\
\text { COVID-19 pandemic... } \\
\text { (multiple answers possible) }\end{array}$ & $\begin{array}{l}\text { I wasn't } \\
\text { stressed }\end{array}$ & $\begin{array}{l}\text { I felt stressed } \\
\text { due to a } \\
\text { possible } \\
\text { infection }\end{array}$ & $\begin{array}{l}\text { I felt stressed } \\
\text { about my } \\
\text { work/job }\end{array}$ & $\begin{array}{l}\text { I felt stressed due } \\
\text { to the general } \\
\text { condition around } \\
\text { the COVID-19 } \\
\text { pandemic }\end{array}$ & $\begin{array}{l}\text { I felt stressed } \\
\text { due to the } \\
\text { uncertainty of } \\
\text { survival }\end{array}$ & other (specify) \\
\hline $\begin{array}{l}\text { 4. During the recent earthquake in } \\
\text { Zagreb, I experienced } \\
\text { injuries/physical destruction to my } \\
\text { apartment/house... }\end{array}$ & $\begin{array}{l}\text { I did not } \\
\text { experience it }\end{array}$ & $\begin{array}{l}\text { I had a } \\
\text { mild/moderate } \\
\text { experience }\end{array}$ & $\begin{array}{l}\text { I had a bad } \\
\text { experience }\end{array}$ & $\begin{array}{l}\text { I experienced it } \\
\text { very much, and } \\
\text { very badly }\end{array}$ & & \\
\hline $\begin{array}{l}\text { 5. The earthquake affected my } \\
\text { psychological condition and stress } \\
\text { level... }\end{array}$ & $\begin{array}{l}\text { I was } \\
\text { unaffected }\end{array}$ & $\begin{array}{l}\text { I was lightly } \\
\text { affected }\end{array}$ & $\begin{array}{l}\text { I was } \\
\text { moderately } \\
\text { affected }\end{array}$ & $\begin{array}{l}\text { I was strongly } \\
\text { affected }\end{array}$ & & \\
\hline $\begin{array}{l}\text { 6. My sleep during the period after } \\
\text { the earthquake in relation to the } \\
\text { period previous was... }\end{array}$ & not disturbed & $\begin{array}{l}\text { slightly } \\
\text { disturbed }\end{array}$ & $\begin{array}{l}\text { moderately } \\
\text { disturbed }\end{array}$ & $\begin{array}{l}\text { severely } \\
\text { disturbed }\end{array}$ & & \\
\hline
\end{tabular}

\section{Questions that assess the impact of the two disasters on AD patients (Table 1)}

Patients in Group 2 of our study filled out only questions 1-3 concerning personal habits and AD condition during the COVID-19 pandemic: changes to their skin/disease condition during the last two months (selfassessed); use of therapy for $\mathrm{AD}$; and psychological stress and its causes (self-assessed). Patients from Group 3 answered all three questions, plus three additional questions that considered the psychological and physical (destructive) effects of the earthquake on them and their subjective experience of earthquake-related stress and sleep disturbances.

\section{Statistical analysis}

Normality of distribution was tested using the Kolmogorov-Smirnov test. Differences in stress and severity of eczema between groups was evaluated with the Kruskal-Wallis test with the post-hoc Mann-Whitney test and Bonferroni correction for multiple comparisons. Correlations between scalar variables (age, PSS and SCORAD) were explored by visual inspection of scatter plots and calculation with the Spearman correlation coefficient. Comparisons of scalar variables between two categories (e.g. gender) were done with the Mann-Whitney test for data with a normal distribution and using the t-test for data that did not have normal distribution. The Wilcoxon test was used for the comparison of itching due to COVID-19 and the earthquake in the group exposed to both disasters. For the comparison of proportions, the $\chi^{2}$ test was used. Effect size, i.e., the magnitude of the difference between groups, was quantified by $r$ according to the formula $\mathrm{r}=\sqrt{ }\left(\mathrm{t}^{2} /\left(\mathrm{t}^{2}+\mathrm{df}\right)\right)(\mathrm{t}=\mathrm{t}$-statistics; $\mathrm{df}=$ degrees of freedom) for $\mathrm{t}$-test or $\mathrm{r}=\mathrm{Z} / \sqrt{ } \mathrm{N}(\mathrm{Z}=\mathrm{Z}$-statistics; $\mathrm{N}=$ number of cases) for the Mann-Whitney test. The Cohen criteria were used for interpretation: $\mathrm{r}=0.1-0.3=$ small effect size, $0.3-0.5=$ medium, $0.5-0.7$ large and $>0.7=$ very large effect size. Effect size for $\chi^{2}$ (Cramer's V or Kendall's $\tau$ ) was interpreted in a similar manner. The Kruskall-Wallis test was estimated by $\varepsilon^{2}$ and for interpretation, the squared value of $r$ was used.

\section{RESULTS}

The study sample included 150 subjects with $\mathrm{AD}$ (73\% females, 27\% males) aged 18-73 years (median 30; IQR 23-45). Age and gender distributions did not differ between the three groups. According to their answers, none of the surveyed AD patients had been infected by SARS-CoV-2.

\section{Results of analysis of PSS and SCORAD values for the three subject groups}

The results of analysis of PSS and SCORAD values for the three subject groups are presented in figures 1, 2 and 3 and Table 2. When comparing PSS values among the three groups, stress levels varied with a small effect size $\left(p=0.011 ; \varepsilon^{2}=0.061\right.$; Table 2$)$ (shown in Figure 2). Group 3 (patients who experienced both the pandemic and the earthquake) had higher stress levels than those experiencing only the COVID-19 pandemic, but stress levels of patients in Group 2 did not differ from the subjects who experienced neither disaster (Group 1).

Subjects in Group 3 had a higher severity of AD (higher SCORAD score) than Group 2 (patients who experienced only the COVID-19 pandemic) and Group 1 , with a medium effect size $\left(\mathrm{p}<0.001 ; \varepsilon^{2}=0.143\right.$; Table 2) (shown in Figure 1). 
Table 2. Age and SCORAD and PSS values for the three AD groups $(\mathrm{N}=150)$

\begin{tabular}{llcccc}
\hline Variable & Group & Median & IQR & $\mathrm{p}$ & $\varepsilon^{2}$ \\
\hline Age & before COVID-19 and earthquake & 28.5 & $23-39.3$ & & \\
& COVID-19 & 33 & $21.8-52$ & & 0.038 \\
\multirow{2}{*}{ SCORAD } & COVID-19 and earthquake & 29.5 & $24-46.5$ & 0.342 & \\
& before COVID-19 and earthquake & $16.5^{\mathrm{a}}$ & $2-38$ & & \\
& COVID-19 & $23.5^{\mathrm{a}}$ & $14.75-31.25$ & & \\
\multirow{5}{*}{ PSS } & COVID-19 and earthquake & $36^{\mathrm{b}}$ & $24.5-48$ & $<0.001$ & \\
& before COVID-19 and earthquake & $18^{\mathrm{ab}}$ & $15-23.25$ & & \\
& COVID-19 & $15^{\mathrm{a}}$ & $12-20$ & & \\
& COVID-19 and earthquake & $19^{\mathrm{b}}$ & $16-23$ & 0.011 & 0.061 \\
\hline
\end{tabular}

IQR-interquartile range, $p$-level of significance for Kruskall-Wallis test, $\varepsilon^{2}$-effect size. Groups that do not share the same superscript letters differ significantly

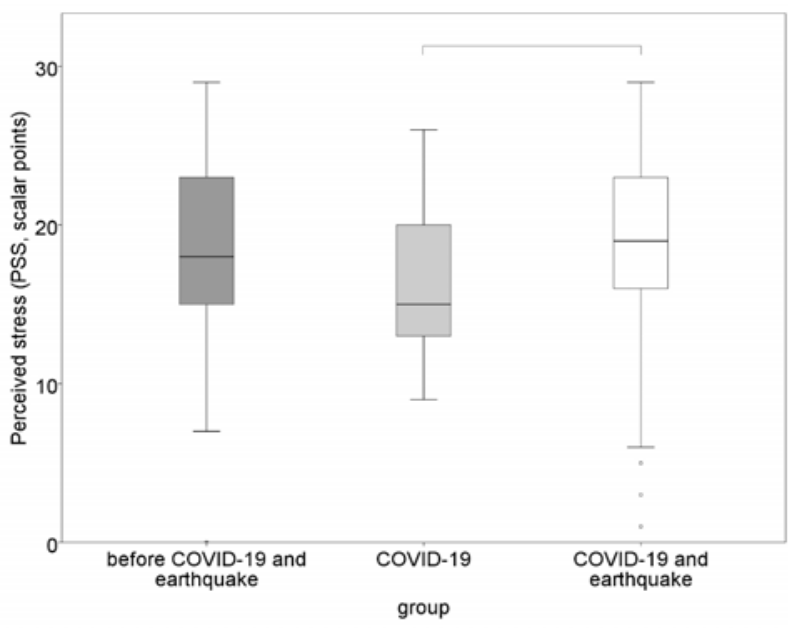

Figure 2. Comparison of perceived stress (PSS) levels between the three subject groups $(\mathrm{N}=150)$

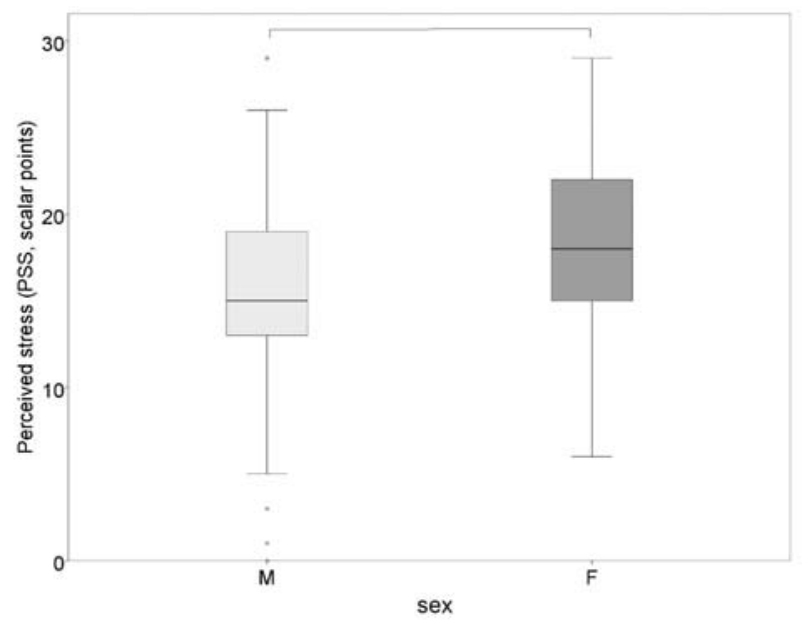

Figure 3. Comparison of level of stress (PSS) by sex between the three subject groups $(\mathrm{N}=150)$

The analysis of PSS and SCORAD values for the three subject groups showed that there were no statistically significant differences in age and gender between them, even though Group 1 had a smaller age range, and had a slightly smaller percentage of women. Concerning age and gender, patient age did not correlate with PSS and SCORAD, but women had a higher degree of stress than men, with a low effect size [median (interquartile range): 18 (15-22) vs. 15 (13-19); $\mathrm{p}=0.004 ; \mathrm{r}=0.233$ ] (shown in Figure 3 ).

\section{The impact of the COVID pandemic on the subjective impression of the skin condition (question 1 of our questionnaire)}

AD patients from Group 3 reported greater deterioration in their skin condition than those who experienced only the COVID-19 pandemic, with moderate effect size [median (interquartile range): 2 (1-3) vs. 1 (02); $p<0.001 ; r=0.359$ ] (shown in Figure 4). Major disease changes (deterioration) were significantly more often observed in the Group 3 than in the Group 2 (26 vs 4\%). Also, an unchanged condition/status was less frequently observed in Group 3 ( 8 vs. 28\%; $p=0.002 ; \tau=0.332$ ).

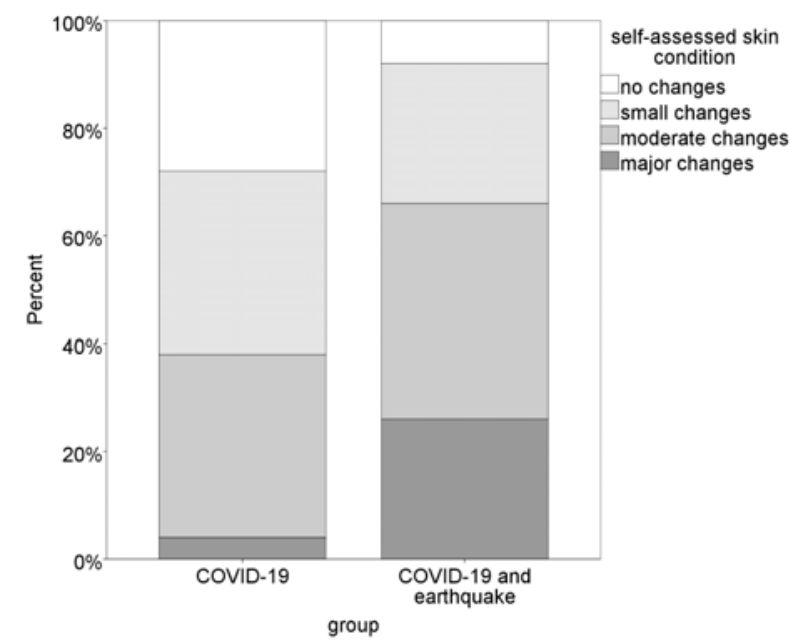

Figure 4. Self-assesed skin condition for subject groups 2 and $3(\mathrm{~N}=100)$

Use of therapy during the COVID-19 pandemic in relation to disease severity (SCORAD) (question 2 of our questionnaire)

Our research on the $100 \mathrm{AD}$ patients who experienced the COVID-19 pandemic demonstrated that the use of therapy during the pandemic was linearly 
moderately positively associated with disease severity $(\mathrm{r}=0.506 ; \mathrm{p}<0.001)$ (shown in Figure 5). The increase in frequency of therapy followed the severity of $\mathrm{AD}$. Patients who were in need of therapy during the pandemic did not differ by level of education or gender. A comparison of eczema/disease severity (determined by SCORAD) and therapy use categories in $\mathrm{AD}$ patients is shown in Figure 5.

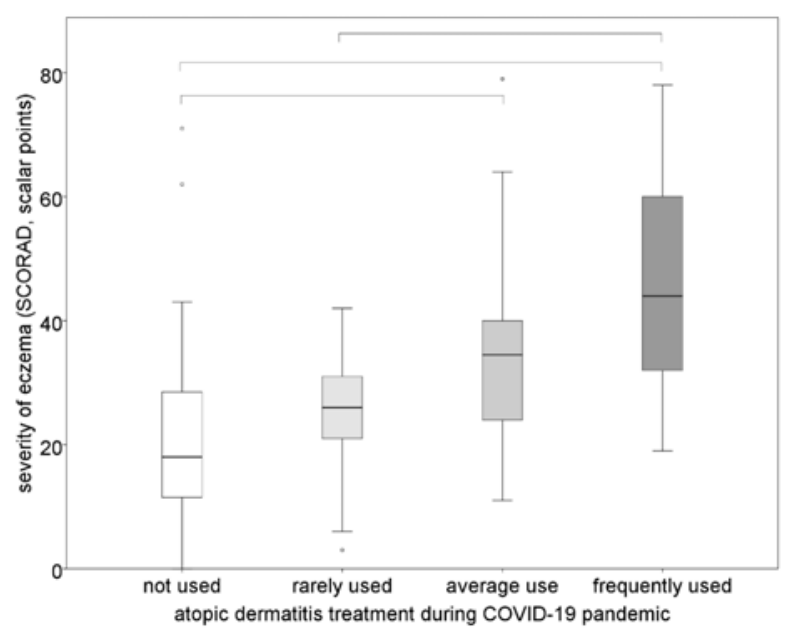

Figure 5. Use of therapy during the COVID-19 pandemic in relation to $\mathrm{AD}$ severity (SCORAD) $(\mathrm{N}=100)$

\section{Self-reported psychological stress and reported causes of stress (question 3 of our questionnaire)}

Answers show that 59\% AD patients reported psychological stress, while $41 \%$ reported that they did not feel psychological stress. Among those with reported stress, the most common cause of the stress was a possible SARS-CoV-2 infection (31\%), followed by work-related stress $(23 \%)$, stress due to new general conditions during the pandemic (17\%), and stress due to the uncertainty of survival (11\%) and other causes $(6 \%)$ (shown in Figure 6). Multiple answers in the survey were possible.

\section{The earthquake's adverse effect on patient PSS and SCORAD scores in comparison to their psychological and physical experiences of the earthquake (questions 4 and 5 of our questionnaire)}

Concerning the earthquake's physical (destructive) effect (injuries and damage to patients' homes), 54\% of patients from Group 3 reported being affected on some level: mildly/moderately (26\%); strongly (14\%); and very strongly $(14 \%)$.

Regarding the earthquake's psychological effects on AD patients' stress levels, the majority of patients reported some level of psychological disturbance (92\%): light effect $(40 \%)$, moderate effect $(24 \%)$ and strong effect $(28 \%)$.

An analysis of patients' responses revealed that their psychological experience of the earthquake was positively, linearly, but weakly correlated with PSS $(r=0.333$; $\mathrm{p}=0.018$ ).

Their physical experience of the earthquake did not correlate with PSS. Neither their psychological nor physical experience correlated with their PSS or SCORAD.

When comparing PSS and SCORAD scores between the categories of responses concerning earthquakerelated subjective stress and stress due to earthquakerelated destruction, the differences were not statistically significant.

\section{The impact of the earthquake on sleep disturbances in relation to PSS and SCORAD scores (question 6 of our questionnaire)}

Concerning sleep disturbances during the period immediately following the earthquake compared to before the earthquake, the majority of patients reported having some level of trouble (64\% patients): light disturbance $(28 \%)$; moderate disturbance $(22 \%)$ and severe disturbance $(14 \%)$. The intensity of earthquake-induced sleep disturbances in $\mathrm{AD}$ patients was moderately linearly positively correlated with stress levels $(r=0.502 ; \mathrm{p}<0.001)$.

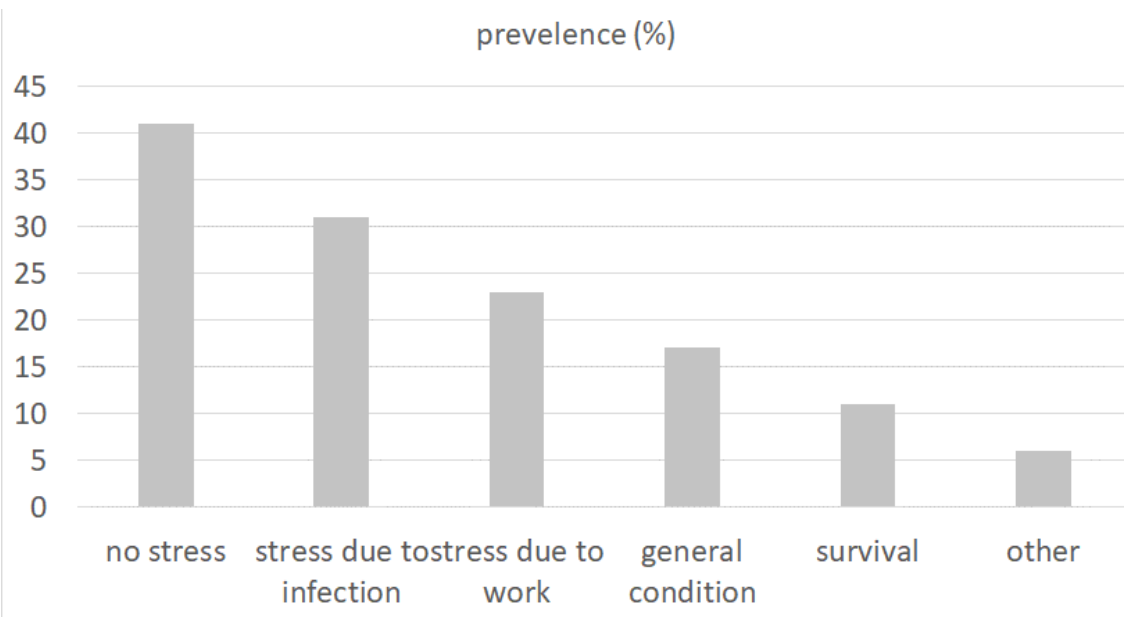

Figure 6. Self-reported causes of psychological stress $(\mathrm{N}=100)$ (multiple answers were possible) 


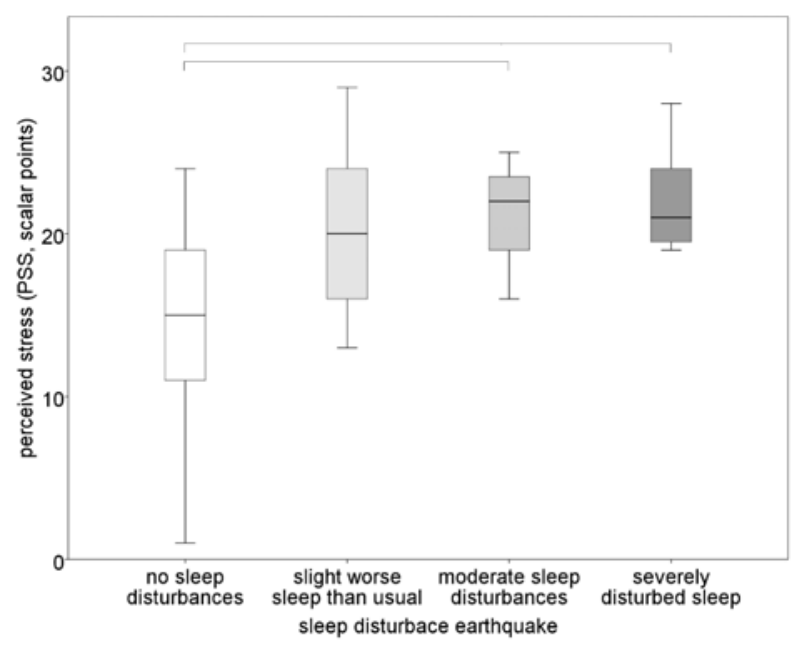

Figure 7. The relationship between PSS scores and earthquake-induced sleep disturbances in $\mathrm{AD}$ patients exposed to the earthquake $(\mathrm{N}=50)$

With the increase of sleep disorders, stress (PSS) increased. Sleep disturbance did not correlate with disease severity (SCORAD). The degree of psychological stress differed significantly between the categories of sleep disorders $\left(p=0.005 ; \varepsilon^{2}=0.253\right)$ (shown in Figure 7). In the figure, horizontal lines connect the patient categories between which the difference was significant.

\section{DISCUSSION}

The current outbreak of the COVID-19 pandemic may have an impact on psychological stress and mental health, especially for those prone to mental disorders and those suffering from various chronic diseases, including chronic skin diseases. Therefore, the World Health Organization has issued technical guidelines concerning the high psychological impact and elevated rates of stress or anxiety, as well as the expected increase in the levels of loneliness, depression, harmful alcohol and drug use, self-harm, or suicidal behavior (World Health Organization: Coronavirus disease (COVID-19) outbreak-technical guidance- EUROPE: mentalhealth and COVID-19 2020). Most of these are a consequence of the newly introduced measures, especially quarantine and its effects on daily activities, routines, and livelihoods (Ćosić et al. 2020, Chernyshov et al. 2020). However, the root of the word quarantine used in English comes from the Italian word quarantina and the Venetian quarantena. Used in the Middle Ages during the outbreaks of Black Death, they both referred to the 40-day period of isolation that a ship's passengers and crew had to be placed under before disembarking (Newman 2012). In 1377, the Venetian port of Ragusa, present-day Dubrovnik in Croatia, became the first place in the world to institute a quarantine. Nowadays, the recent conditions of social isolation during the COVID-19 pandemic in quarantine is a novel experience which may cause major psychological effects such as anxiety and a sense of uncertainty; decreased perception of health; negative social behaviors etc (Gupta et al. 2017, Huremović 2019, Ćosić et al. 2020, Sharma et al. 2020, Garcovich et al. 2020). Such a negative effect of stressful events on the psyche may influence onset, recurrence or worsening of chronic dermatoses such as $\mathrm{AD}$, vulgar psoriasis, chronic urticaria etc. As for $\mathrm{AD}$, numerous experimental and clinical studies have established a relevant association between psychological dysfunctions and AD (LonneRahm et al. 2008, Oh et al. 2010, Senra \& Wollenberg 2014, Lin et al 2017). According to previous research, as many as $70 \%$ of $\mathrm{AD}$ patients experienced some form of stress prior to onset of the disease and more than $70 \%$ of them reported worsening of the/their condition due to stress (Wittkowski et al. 2007). According to our study, AD patients that experienced both disasters had higher disease severity (SCORAD) than those in other two groups and they reported disease deterioration more frequently $(26 \%)$ than those who experienced only the COVID-19 pandemic (4\%), thus confirming the effect of psychological factors and stressful events (such as the pandemic and earthquake) on the course of AD.

Despite the importance of this pandemic's influence on mental health, little research/data has been published. A survey on 5,000 Chinese citizens established that $21.5 \%$ of them had recorded symptoms of post traumatic stress disorder (PTSD) - similar as under the quarantine during the 2003 SARS epidemic, where PTSD was reported by $28.9 \%$ of the citizens and depression by $31.2 \%$ of them (Hawryluck et al. 2004, Kirton 2020, Ćosić et al. 2020). Also, according to a Chinese survey on 2,091 people on the incidence of PTSD symptoms one month after the outbreak, the prevalence in the high-risk population (e.g., in Chinese provinces with higher incidence of COVID-19) was $18.4 \%$, compared to $4.6 \%$ among the mainland China citizens in general (Sun et al 2020). According to a U.S. study on COVID-19 conducted in March 2020, approximately one-third of adults (32\%) felt that the COVID-19-related stress had a negative effect on their mental health and $14 \%$ of them said the effect was "major" (Hamel et al. 2020). According to our results, $59 \%$ of patients reported psychological stress during the pandemic, caused by: possibility of an infection (31\%), influence on their work $(23 \%)$, general pandemicrelated conditions $(17 \%)$, concern on survival $(11 \%)$ and other $(6 \%)$. Also, patient perceived stress levels (PSS) differed between our three AD groups, as the subjects who experienced both disasters had higher stress than those who experienced only the COVID-19 pandemic, although they did not differ from the subjects who experienced neither disaster. This is probably due to general patient characteristics, as the group that experienced neither disaster had a smaller age range, included slightly younger patients, and had a slightly smaller percentage of women, which may be the reason 
why stress was higher in them - e.g., studying, work, parental role. In addition, we assume that for some of our patients their stay in quarantine and absence from their job (which often includes concomitant stress) may have neutralized or lessened the negative influence of COVID-19-induced psychological stress. However, this new psychological effect of the COVID-19 pandemic on patients with chronic diseases such as $\mathrm{AD}$ indicates a necessity for timely actions and a psychological approach to minimize negative effects on mental health (Ćosić et al. 2020).

As far as AD and stress-related major/severe catastrophic events or disasters are concerned, there is no sufficient research. According to a study on AD occurrence after a major earthquake in Hanshin (Japan) by Kodama et al. (conducted among 1,457 AD patients), psychological stress was the most responsible factor for AD exacerbations (Kodama et al. 1999). Deterioration was the most frequent in $\mathrm{AD}$ patients who lived in the area where the earthquake caused major damage $(38 \%$ of patients); it was slightly less frequent in the areas of minor damage (34\% of the patients) and it was the least frequent in the undamaged areas (7\% of the patients). However, when earthquakes occur as an additional to an already ongoing disaster, as was experienced in Croatia, it might significantly affect the psyche of patients with chronic diseases such as $\mathrm{AD}$, and those effects might be longlasting and may have strong longitudinal consequences. According to an analysis of our AD patients' responses, there was positive correlation between their psychological experience of the earthquake and their PSS. Also, stress (PSS) increased with the increase of sleep disorders. This data supports that psychological stress affects $\mathrm{AD}$, especially taking into account that the skin actively responds to psychological stress, with involvement of hormones, skin immune cells and neurotransmitters. Stress-induced skin reactions primarily include cytokine secretion [e.g. interleukins IL-6, IL-1, interferon (IFN)- $\gamma$ )] and activation of skin peripheral corticotropin-releasing hormone $(\mathrm{CRH})$ - proopiomelanocortin (POMC) - adrenocorticotropic hormone, and the $(\mathrm{ACTH})$ - corticosteroids axis, which leads to skin inflammation (Pondeljak \& Lugović-Mihić 2020).

It is also necessary to consider patient self-care when assessing risk factors for development/aggravation of skin lesions, especially on the hands, as frequent hand washing and disinfecting are necessary during the pandemic (Senra \& Wollenberg 2014, Meštrović-Štefekov 2018, Choe et al. 2018, Darlenski \& Tsankov 2020). According to our results concerning the use of AD therapy during the pandemic, it was positively associated with the disease severity (as the AD severity increased, so did the frequency of therapy), indicating its appropriate use. However, skin barrier disturbances could be also related to psychological stress, as previously discussed (psychological stress may trigger or cause exacerbations of the lesions/symptoms, which is explai- ned by various stress hormones produced in the skin and their receptors) proven in the skin (Senra \& Wollenberg 2014, Meštrović-Štefekov 2018, Choe et al. 2018).

Based on the confirmed influence of disasters on AD patients, timely actions are needed to minimize their negative effects on the status of patients' psychological and physical health, including their influence on manifestations of diseases (Ćosić et al. 2020). It is necessary to recognize the early warning signs of psychological disturbances in order to access/ensure safe and confidential resources (Bansal et al. 2020, Shaker et al. 2020, Marshall 2020). Therefore planned, and organized measures (both short-term and long-term ones) are important, including collaboration between different specialists and inclusion of a multidisciplinary team (Shaker et al. 2020). To the best of our knowledge, this is the first study examining the influence of the COVID-19 pandemic on psychological stress in $\mathrm{AD}$ patients, and it is also the first research analyzing the influence of two simultaneous disasters on psychological aspects of patients with a skin disease. We hope that our results will be useful for some new research, for planning further actions and for designing psychological support/therapies for patients with chronic diseases such as AD.

\section{CONCLUSIONS}

Our results confirmed the impact of disasters and adverse events on the AD patients' mental health, psychological stress and disease manifestations, about which there have not been many previous scientific experience/analyses. Clearly, sustained pandemic-induced psychosocial stress may lead to exacerbation, onset or worsening of $\mathrm{AD}$, and may also expand the psychological problems of such patients. Practitioners should therefore be aware of possible early warning signs of patients' psychological problems and diseases. They should also access/ensure safe and confidential resources and therapy in their practice.

\section{Acknowledgements:}

Assistance provided by Prof. Stjepan Špalj, DMD, $\mathrm{MSc}, \mathrm{PhD}$ regarding statistical analysis, and the assistance provided by Mrs. Suzana Salopek regarding English editing was greatly appreciated.

\section{Conflict of interest: None to declare.}

\section{Contribution of individual authors:}

Liborija Lugović-Mihić: drafting the manuiscript and critical revision of the manuscript for important intellectual content.

Jelena Meštrović-Štefekov, Mirna Tomljenović-Veselski \& Hrvoje Cvitanović: collecting data and support in writting.

Nives Pondeljak \& Marina Dasović: collecting of data, participating in drafting of the manuscript. 


\section{References}

1. Bansal P, Bingemann TA, Greenhawt M, Mosnaim G, Nanda A, Oppenheimer $J$ et al.: Clinician wellness during the COVID-19 pandemic: extraordinary times and unusual challenges for the allergist/immunologist. $J$ Allergy Clin Immunol Pract 2020;8:1781-1790.e3

2. Chernyshov PV, Tomas-Aragones L, Augustin M, Svensson A, Bewley A \& Poot F: Position Statement of the European Academy of Dermatology and Venereology task force on quality of life and patient oriented outcomes on quality of life issues in dermatologic patients during the COVID-19 Pandemic. J Eur Acad Dermatol Venereol 2020; 34:1666-1671

3. Choe SJ, Kim D, Kim EJ, Ahn JS, Choi EJ, Son ED et al.: Psychological stress deteriorates skin barrier function by activating 11 $\beta$-hydroxysteroid dehydrogenase 1 and the HPA Axis. Sci Rep 2018; 8:6334

4. Cohen S, Kamarck $T$ \& Mermelstein R: A global measure of perceived stress. J Health Soc Behav 1983; 24:386-396

5. Civljak R, Markotić A \& Capak K: Earthquake in the time of COVID-19: The story from Croatia (CroVID-20). $J$ Glob Health 2020;10:010349

6. Ćosić K, Popović S, Šarlija $M$ \& Kesedžić I: Impact of human disasters and COVID-19 pandemic on mental health: potential of digital psychiatry. Psychiatr Danub 2020; 32:25-31

7. Darlenski $R \&$ Tsankov N: COVID-19 pandemic and the skin: what should dermatologists know?. Clin Dermatol 2020;38:785-787.

8. Fazlić H, Brborović O, Vukušić Rukavina T, Fišter K, Milošević $M \&$ \&ustajbegović J: Characteristics of people with the perceived stress in Croatia: the CroHort Study. Coll Antropol 2012;36(Suppl. 1):165-169

9. Garcovich S, Bersani FS, Chiricozzi A \& De Simone C: Mass quarantine measures in the time of COVID-19 pandemic: psycho-social implications for chronic skin conditions and a call for qualitative studies. J Eur Acad Dermatol Venereol 2020;34:e293-294.

10. Gupta MA, Jarosz P \& Gupta AK: Posttraumatic stress disorder (PTSD) and the dermatology patient. Clin Dermatol 2017; 35:260-266.

11. Hamel L, Lopes L, Muñana C, Kates J, Michaud J \& Brodie M: KFF coronavirus poll: March 2020. Available at: https://www.kff.org/global-health-policy/poll-finding/ kffcoronavirus-poll-march-2020/. (last accessed May 29, 2020)

12. Hanifin JM \& Rajka G: Diagnostic features of atopic dermatitis. Acta Derm Venereol 1980; 92:44-47

13. Hawryluck L, Gold WL, Robinson S, Pogorski S, Galea S \& Styra R: SARS control and psychological effects of quarantine, Toronto, Canada. Emerg Infect Dis 2004; 10:1206-1212

14. Honeyman JF: Psychoneuroimmunology and the skin. Acta Derm Venereol 2016; 96:38-46

15. Huremović D: Mental Health of Quarantine and Isolation. In: Huremović D (eds): Psychiatry of pandemics, 95-118. Basel: Springer Nature Switzerland AG, 2019

16. Kirton D: Chinese public dial in for support as coronavirus takes mental toll. Reuters, February 13, 2020. Available at: https://www.reuters.com/article/uschina-health-mental/chinese-public-dial-in-for-support-
as-coronavirus-takes-mental-toll-idUSKBN2070H2. (last accessed July 1, 2020.)

17. Kodama A, Horikawa T, Suzuki T, Ajiki W, Takashima T, Harada $S$ et al.: Effect of stress on atopic dermatitis: investigation in patients after the great hanshin earthquake. J Allergy Clin Immunol 1999;104:173-6

18. Kunz B, Oranje AP, Labrèze L, Stalder JF, Ring $J$ \& Taieb A: Clinical validation and guidelines for the SCORAD index: Consensus report of the European Task Force on Atopic Dermatitis. Dermatology 1997; 195:10-19

19. Lin TK, Zhong L \& Santiago JL: Association between stress and the HPA axis in the atopic dermatitis. Int $J$ Mol Sci 2017; 18:2131

20. Lonne-Rahm SB, Rickberg H, El-Nour H, Mårin P, Azmitia EC \& Nordlind K: Neuroimmune mechanisms in patients with atopic dermatitis during chronic stress. $J$ Eur Acad Dermatol Venereol 2008;22:11-18.

21. Lugović-Mihić L, Ljubesić L, Mihić J, Vuković-Cvetković $V$, Troskot $N$ \& Šitum M: Psychoneuroimmunologic aspects of skin diseases. Acta Clin Croat 2013; 52:337345

22. Marshall GD Jr: Psychological stress, immune dysfunction, and allergy: Opportunities for improved patient health. Ann Allergy Asthma Immunol 2020; 125:365-366

23. Meštrović-Štefekov J, Novak-Bilić G, Kuna M, Pap $N$ \& Lugović-Mihić L: Psychological stress in patients with atopic dermatitis. Acta Dermatovenerol Croat 2018; 26:297-303

24. Newman Dorland: W. A. Dorland's Illustrated Medical Dictionary 32nd, Philadelphia: Elsevier Saunders; 2012

25. Oh SH, Bae BG, Park CO, Noh JY, Park IH, Wu WH et al.: Association of stress with symptoms of atopic dermatitis. Acta Derm Venereol 2010; 90:582-588

26. Pondeljak $N \&$ Lugović-Mihić L: Stress-induced interaction of skin immune cells, hormones, and neurotransmitters. Clin Ther 2020; 42:757-770

27. Rønnstad ATM, Halling-Overgaard AS, Hamann CR, Skov L, Egeberg A \& Thyssen J: Association of atopic dermatitis with depression, anxiety, and suicidal ideation in children and adults: A systematic review and metaanalysis. J Am Acad Dermatol 2018; 79:448-456.e30

28. Senra MS \& Wollenberg A: Psychodermatological aspects of atopic dermatitis. Br J Dermatol 2014;170 Suppl 1:38-43

29. Shaker MS, Oppenheimer J, Grayson M, Stukus D, Hartog $N$ \& Hsieh EWY COVID-19: Pandemic contingency planning for the allergy and immunology clinic. $J$ Allergy Clin Immunol Pract 2020;8:1477-1488.e5

30. Sharma A, Fölster-Holst R, Kassir M, Szepietowski J, Jafferany M, Lotti $T$ et al.: The effect of quarantine and isolation for COVID-19 in general population and dermatologic treatments. Dermatol Ther 2020;e13398.

31. Silverberg JI, Gelfand JM, Margolis DJ, Boguniewicz M, Fonacier L, Grayson MH et al.: Symptoms and diagnosis of anxiety and depression in atopic dermatitis in U.S. adults. Br J Dermatol 2019;181:554-565

32. Suárez AL, Feramisco JD, Koo $J$ \& Steinhoff $M$ : Psychoneuroimmunology of psychological stress and atopic dermatitis: pathophysiologic and therapeutic updates. Acta Derm Venereol 2012;92:7-15 
33. Sun L, Sun Z, Wu L, Zhu Z, Zhang F, Shang $Z$ et al.: Prevalence and risk factors of acute posttraumatic stress symptoms during the COVID-19 outbreak in Wuhan. medRxiv 2020.03.06.20032425

34. Trkulja $V$ \& Hrabač P: Meta-analysis is not always the best way to round out a systematic review: a few thoughts prompted by the COVID-19 pandemic and "spiced-up" with an earthquake. Croat Med J 2020;61:198-200

35. Wittkowski A, Richards HL, Griffiths CE \& Main CJ: Illness perception in individuals with atopic dermatitis. Psychol Health Med 2007;12:433-444
36. World Health Organization: Coronavirus disease (COVID-19) outbreak - technical guidance - EUROPE: mentalhealth and COVID-19. 2020. Available at: http://www.euro.who.int/en/health-topics/healthemergencies/coronavirus-covid-19/novel-coronavirus2019-ncov-technical-guidance/coronavirus-diseasecovid-19-outbreak-technicalguidance-europe/mentalhealth-and-covid-19. (last accessed June 15, 2020)

\section{Correspondence:}

Professor Liborija Lugović-Mihić, MD, PhD

Department of Dermatology and Venereology, University Hospital Centre Sestre Milosrdnice Vinogradska Cesta 29, 10000 Zagreb, Croatia

E-mail: liborija@gmail.com 